\title{
Is Spatial Orientation Affected by Ramadan Fasting?
}

\begin{tabular}{|r|l|}
\hline Journal: & Nutrition and Food Science \\
\hline Manuscript ID & NFS-08-2018-0224.R4 \\
\hline Manuscript Type: & Original Article \\
\hline Keywords: & $\begin{array}{l}\text { Ramadan Fasting, Spatial orientation, Computerized Rod and Frame Test } \\
\text { (CRFT) }\end{array}$ \\
\hline \multicolumn{2}{|c}{} \\
\hline
\end{tabular}

\section{SCHOLARONE \\ Manuscripts}




\section{Abstract}

Purpose- Ramadan intermittent fasting (RIF) has produced heterogeneous and domain-specific effects on cognitive function. The present study investigates the effect of RIF on verticality perception or estimation of subjective visual vertical (SVV) in young adults. The significance of SVV is that it is essential for spatial orientation, upon which many daily activities depend.

Methodology - Verticality perception was assessed with a computerized version of the Rod and Frame Test (CRFT) in two visual conditions: without a surrounding frame, and with a distracting tilted frame. The tilted frame condition measures level of visual dependence, or reliance of visual cues for posture and orientation. 39 young adult male males were recruited at different stages of Ramadan fasting: 21 were tested at the end of the first week (Week 1) and 18 others at the end of the third week (Week 3) of Ramadan. 39 participants were also recruited to serve as a non-fasting control group. Factorial ANOVA analyses were conducted to identify the main effects of fasting status, time-of-day and the interaction between them on blood glucose levels, nocturnal sleep duration and vertical alignment errors.

Findings- The main effect of fasting status on glucose level was significant $(P=0.03)$. There was a significant time-of-day main effect on glucose levels $(P=0.007)$ and sleep duration $(P=0.004)$ only in fasting participants. Neither the main effects of fasting status nor time-of-day were significant for rod alignment errors in both visual conditions. The interaction of fasting status and time-of-day was not significant either. This may indicate that any negative effect of Ramadan fasting on activities that are critically dependent on verticality perception and spatial orientation, such as sports and driving, may not be due to verticality misperception.

Originality- The present study was the first to investigate the effect of Ramadan fasting on spatial orientation. It demonstrated robustness of verticality perception to fasting status and the point of fasting during Ramadan. Verticality perception was also unaffected by time of day effects in nonfasting and fasting groups at two different points of Ramadan. This study corroborates others reporting heterogeneous effects of Ramadan fasting on cognitive function.

Key Words- Ramadan Fasting, Spatial orientation, Computerized Rod and Frame Test (CRFT) 


\section{Introduction}

Studying the effect of Ramadan intermittent fasting (RIF) on cognitive function is quite significant considering that every year millions of Muslims around the world observe the ritual of fasting for 29 - 30 days during the month of Ramadan, the ninth month of the lunar calendar. Ramadan fasting entails abstaining from eating, drinking, and smoking from dawn to dusk, with free consumption of food and fluids at night (Chtouru et al., 2012; Souissi et al., 2014), leading to changes in feeding habits, sleep cycle (Roky et al., 2003; Waterhouse 2010) and other circadian rhythms (Reilly \& Edwards, 2007; Roky et al., 2012). Previous studies investigating cognitive function during Ramadan fasting have produced conflicting results. Adverse effects in perceptual sensitivity, subjective alertness, continuous attention and memory functions (Ali \& Amir, 1989; Hakkou et al., 1988; Roky et al., 2000; Dolu et al., 2007) and reaction times (Farooq et al., 2015) have been reported. However, evidence also exists regarding the relative robustness of reaction time, visual information processing, arousal and short term memory (Chamari et al., 2016; Dolu et al., 2007; Najafabadi et al., 2015) and non-speed dependent accuracy measures (Alsharidah et al., 2016).

It is important to learn whether Ramadan fasting can affect spatial orientation abilities in humans considering that spatial orientation is a fundamental component of many spatial cognitive behaviors such as ambulatory navigation (Simmons, 2003), driving (Kemeny \& Panerai, 2003) and sports (Higazi, 2013; Romeas \& Faubert, 2013). Spatial orientation relies on intact abilities such as verticality perception or estimation of subjective visual vertical (SVV). The significance of SVV lies in its ability to measure the accuracy by which individuals internally represent their position in space relative to gravity. Such internal estimates of the direction of gravity are continuously updated because of frequent changes in head and trunk positions, using visual input from the eyes, proprioceptive input from skin and joints, and most importantly, input about linear acceleration and the pull of gravity from the otolith organs (Vingerhoets et al., 2009). As such, SVV perception is a very important factor for spatial orientation and the maintenance of posture and equilibrium (Mazibrada et al., 2008). 
Verticality perception has been reported to fluctuate throughout the day, with gradual deterioration over the day (Zouabi et al., 2016). This is in line with other studies that demonstrated the presence of circadian rhythms in cognitive ability over the course of the day (Pollack et al., 1992; Monk, 1997; Monk, 2005). Such time-of day effects may be maintained during Ramadan fasting, but potential confounders such as changes in sleep-wake cycle, food and fluid intakes, and natural circadian rhythms may disrupt them. A published study on cognitive performance during Ramadan fasting has considered this and reported surfacing of time-of-day effects that were nonexistent during non-fasting state. The authors of that study concluded that the effects of Ramadan fasting often reflected poorer afternoon performance (Tian et al., 2011) and attributed this effect to the combination of lowered blood glucose levels in the afternoon and sleep restriction.

Our study was designed to examine the effect of fasting during Ramadan on verticality perception. We aimed to identify whether verticality perception was governed by circadian rhythms in nonfasting controls. We also tried to determine whether changes in blood glucose levels and circadian rhythms arising from the alterations in feeding and sleep schedules during Ramadan would affect verticality perception. Since some cognitive functions deteriorate significantly by the end of the day with fasting (Tian et al., 2011), it might be expected that verticality perception would also be compromised towards the end of the day, when blood glucose are lower (Bonakdaran, 2016). The importance of this study lies in that any potential negative consequences of Ramadan fasting on verticality perception may increase susceptibility to spatial disorientation and impact upon the individual's ability to successfully engage in activities critically dependent on spatial orientation.

\section{Methodology \\ Participants}

Participants did not receive any incentives for their participation, and they all gave written informed consent. The study was approved by the Research and Ethics committee at the Arabian Gulf University (AGU). Seventy eight healthy young active college male medical students (age range from 18 - 23 years) were recruited for this study at the College of Medicine and Medical Sciences at AGU in Bahrain. Thirty nine participants were fasting during Ramadan of the year 
2016 (June 6 - July 5). The minimum duration of daily fast from dawn (3:12 - 3:18 am) to dusk $(6: 29-6: 35 \mathrm{pm})$ was around 15 hours. Participants in the fasting group were asked verbally to confirm their Ramadan fasting status up to the day of the test. They were recruited at different stages of Ramadan fasting: twenty one participants were tested at the end of the first week of Ramadan (Week 1) and eighteen others at the end of the third week of Ramadan (Week 3), in order to reduce possible testing bias arising at the beginning of Ramadan when the body has not fully adapted to changes in feeding habits, sleep cycles (Rocky et al., 2003; Waterhouse, 2010) and other circadian rhythms (Rocky et al., 2012; Reilly \& Edwards, 2007). Thirty nine participants were also recruited a few months after Ramadan to serve as non-fasting control group. Information on the number of hours of nocturnal sleep the night before the test trial as well as on the quantity of sleep in general was obtained from all participants.

Blood glucose levels were measured at the beginning of the test using an ACCU-CHEK ACTIVE (Roche, Germany) glucometer for non-fasting and fasting participants. Studies on the accuracy of capillary glucose meter readings have demonstrated an appropriate accuracy and a plausible correlation between Accu-Chek glucometer and the standard laboratory approach (Nooripoor et al, 2012; Kermani et al, 2017).

\section{Assessment of Verticality Perception}

In this study, verticality perception was assessed in a non-fasting group outside the month of Ramadan and two other fasting groups at two points of Ramadan. This was carried out at two times of day allowing characterization of the interaction between time-of-day and fasting effects. For factoring in the time-of-day effects at testing, participants were grouped into Morning and Afternoon groups, in which testing occurred between 9:00 and 10:00 am and 4:00 and 5:00 pm for the morning and afternoon sessions respectively.

We have utilized a modified computerized version (Bagust, 2005; Docherty \& Bagust, 2010) of the Rod and Frame test (RFT) to assess verticality perception. Generally, the RFT is a clinical exam that evaluates a subject's ability to align a line to vertical position, with the recorded 
In the current study, the rod display on the CRFT was not represented by a line, but consisted of five white dots displayed in the center of the screen (Docherty \& Bagust, 2010) with one of two starting positions - tilted 20 degrees in either a clockwise or counter clockwise direction from gravitational vertical. There were also three possible presentations of the surrounding white frame: frame absent (SVV, No frame); frame tilted 18 degrees in a clockwise direction (frame ${ }^{+18^{\circ}}$ ); or tilted 18 degrees in a counter-clockwise direction $\left(\right.$ frame $^{-18^{\circ}}$ ). The CRF test comprised 12 presentations and consisted of four replicates of each frame presentation (Fig 1). The order of presentation of these permutations of frame and dots was assigned by the computer from 4 randomized sequences. A round black paper ring was attached over the screen of laptop used to display the test. This served to conceal the edges and reduce clues to verticality, while exposing the rod and frame presentation in the center of the screen (Fig 1). The test was performed in a dark room minimizing further any vertical cues within the room.

\section{Procedure and Error Calculations}

Prior to beginning the test, participants were shown two instructional presentations: one with the frame absent (SVV) and one where the frame was tilted. This allowed them to familiarize themselves with the process. The results from these two presentations were not included in the analysis. During testing, participants were seated in front of the laptop screen and were asked to 
look straight at the screen keeping their head in a fixed position without tilting or turning. They were instructed to rotate the dots using the right and left mouse buttons to a position perceived to be vertical. The dots rotated around their virtual midpoint in 0.5 degree increments. When the participant was satisfied with the alignment of the dots, the program was advanced using the space bar of the computer keyboard. Positioning errors were recorded by the computer in degrees from gravitational vertical $\left(0^{\circ}\right)$. The recorded errors were only accessible at the end of the recording session.

Deviations from vertical were recorded in degrees. These values were imported into Excel 2003 and used to calculate the mean absolute (unsigned) errors for the three frame conditions ( $\mathrm{n}=4$ in each case) for each participant. A paired t-test comparing individual's errors when the frame was tilted clockwise to those produced when the frame was presented with a counter clockwise tilt revealed no significant differences between the two measures for non-fasting, Week 1 and Week 3 fasting groups. As a result the mean errors for each tilted frame condition were combined to form a mean tilted frame score denoted by Mean ${ }^{18}$.

\section{Statistical Analysis}

All statistical analyses were carried out using SPSS Statistics 23 (IBM). Data were tested for normality using the Kolmogorov-Smirnoff method. Two-way analyses of variance were conducted on the influence of two independent variables (Fasting status, Time-of-day) on a) blood glucose levels, b) sleep duration and c) alignment errors (SVV and Mean ${ }^{18}$ ). Fasting status included three levels (Non-fasting, Week1, and Week3) and time of day consisted of two levels (Morning, Afternoon). Week1 and Week3 indicates testing at the end of Week1 and Week3 of Ramadan fasting. Post hoc analyses were conducted using the Bonferroni test. Data were reported as mean \pm SD, and level of significance was set at $P<0.05$.

\section{Results}




\section{Blood Glucose Levels}

Blood glucose level ranged between 62 and $117 \mathrm{mg} / \mathrm{dl}$ in the non-fasting group and between 61 and $103 \mathrm{mg} / \mathrm{dl}$ in the fasting group. The main effect of fasting status on glucose level yielded a significant $(P=0.03)$ difference in glucose levels between non-fasting, fasting Week 1 and fasting Week 3 of Ramadan groups. Pairwise comparisons for the main effect of glucose level corrected using a Bonferroni adjustment indicated that the mean glucose level in the non-fasting group was significantly higher than Week 3 fasting group $(P=0.03)$. However, Week 1 fasting did not significantly differ from Week3 and non-fasting status. Simple main effect analysis showed that only for Afternoon sessions, the mean glucose level at Week3 was significantly lower than in the non-fasting state $(P<0.001)$.

There was a significant $(P=0.007)$ main effect of time-of-day on blood glucose level. Post hoc analysis revealed differences between the two sessions within the Week $1(P=0.005)$ and Week 3 $(P=0.009)$ of Ramadan, but not within the non-fasting sessions. However, the interaction of fasting status and TOD was not significant.

\section{Sleep Duration}

In the fasting participants, sleep duration the night prior to the test ranged from no sleep ( 0 hours) to 8 hours. The range was 2 to 12 hours for the non-fasting group. Most participants however explained that these sleep durations were not consistent every night. Fasting status had no 
significant main effect on sleep duration, while time-of-day for testing did $(P=0.004)$. Participants who were tested in the afternoon reported longer hours of nocturnal sleep, however post-hoc analysis showed that the difference was significant only for the fasting participants (Week 1: $P=0.04$; Week 3: $P=0.03$ ). The interaction of fasting status and time-of-day was not significant for sleep duration.

\section{Discussion}

The present study investigated the effect of Ramadan intermittent fasting on a cognitive task of spatial perception, namely verticality perception in healthy young adults by using a computerized version the Rod and Frame test. In both fasting and non-fasting groups, verticality perception assessment was performed at either of two times of day, in the morning or late afternoon. To be able to detect possible differences between the morning and late afternoon when comparing fasting with non-fasting participants, the present study kept a common time of testing for absolute comparison purposes.

The current study showed no impact of Ramadan fasting on verticality perception in healthy young adults. There were no significant differences in rod alignment errors in any visual condition according to fasting status, indicating that non-fasting and fasting individuals at early Ramadan and later in Ramadan had comparable verticality perception. Our results of a lack of time-of-day effect for testing in non-fasting participants indicate that verticality perception was not governed by natural circadian rhythms and are contrary to Zouabi’s (2016) findings. We also did not find any differences in verticality perception between morning and afternoon sessions in fasting participants at both points of Ramadan. This may indicate that the change in circadian rhythms during Ramadan fasting did not affect the robustness of verticality perception to time-and-day effects. The current results are not in accord with other studies on the effect of religious fasts on spatial abilities. According to Doniger et al. (2006), a 12-16 hour Jewish religious fast adversely affects spatial perception in the afternoon. Another study on the effect of Ramadan fasting on spatial skills in preteens and teenage boys showed improvement of spatial planning abilities in these children (Farooq et al., 2015). However that study was deficient in that it only evaluated the children's spatial planning ability in the morning, excluding testing near the end of the day. 
Our results of a significant time-of-day effect on blood glucose, with a significant reduction in the afternoon concur with recent Ramadan fasting study in which glucose level dropped slightly with longer than 12 hour Ramadan fast and was maintained at $60-70 \mathrm{mg} / \mathrm{dl}$ (Bonakdaran, 2016). In the current study, even though there was a significant time-of-day effect on blood glucose levels in fasting participants at both 1 week and 3 weeks of Ramadan, fasting showed no effect on verticality perception, not even in the afternoon when glucose levels were lower. It is intuitive to think that brain areas involved in SVV processing could suffer from low glucose levels, considering that there is increased neural activity during SVV judgment and alignment tasks in brain areas representing the neural basis of spatial reference frames (Lopez et al., 2005). Such increased neural activity is normally accompanied by increased energy expenditure, so glucose limitation may adversely affect such a spatial task. However this may not be the case as profound cognitive disturbances usually occur at blood glucose levels of $50 \mathrm{mg} / \mathrm{dl}$ (William \& Hemmen, 2011), less than the levels reached in the current study. Therefore the preserved verticality perception in the fasting condition may be partly related to tight endogenous regulation of blood glucose levels through counter-regulatory hormones such as glucagon and epinephrine secreted in response to a fall in blood glucose and mobilization of glycogen resources and compensatory gluconeogenesis mechanisms (Azizi, 2010; Sprague \& Arbelaez, 2011; Bonakdaran, 2016)

It is established that some cognitive functions such as psychomotor and cognitive speed, vigilance and executive attention, working memory, and cognitive abilities can be affected by sleep loss (Durmer \& Dinges, 2005). However, there have been conflicting reports regarding the influence of sleep alteration during Ramadan on cognitive function. Several studies assessing the sleep patterns of Medical students and teenage boys during Ramadan fasting reported delayed bedtime, a significant reduction in nocturnal sleep and alterations in the basic structural organization of normal sleep (rapid eye movement (REM) sleep and non-REM (NREM) sleep stages), (Margolis $\&$ Reed, 2004; Farooq et al, 2015). These findings also showed that sleep loss might be responsible for excessive fatigue and reduced alertness in the daytime. On the other hand, others reported no effect of Ramadan fasting on daytime sleepiness, the arousal index, drowsiness or vigilance, 
despite of the impacted sleep architecture/schedule during Ramadan, suggesting no potential major effect of these variables on cognitive function (Bahammam et al., 2013a,; 2013b; 2014).

In the current study, we found no significant difference in nocturnal sleep duration between nonfasting, and Week1 or Week 3 groups. However, fasting groups tested in the morning generally obtained two less hours of sleep than the fasting participants tested in the afternoon. This may be due to two reasons: first participants scheduled to attend the morning testing sessions had to wake up earlier than those for the afternoon sessions, and more importantly, bedtime is delayed during Ramadan. Despite of the fewer sleeping hours, there were no significant differences in any verticality perception measures. These findings suggest that sleep restriction is not a confounding factor associated to Ramadan fasting in this study. Additionally, the non-chronic sleep restriction for our participants who slept for shorter hours the night before testing, and the individual difference in the degree of cognitive vulnerability to sleep loss (Durmer \& Dinges, 2005) may explain the robustness of verticality perception to sleep loss in our fasting participants.

In reference to daily functional correlates, our findings are important and may indicate that the negative effect of Ramadan fasting on activities that are critically dependent on verticality perception and spatial orientation may not be due to verticality misperception. An example is the reduction of static and dynamic postural control during Ramadan fasting in athletes (Souissi et al., 2012 \& 2014). This may also be applicable to the reported negative effects of Ramadan fasting on vehicle driving, which critically depends on spatial orientation (Kemeny \& Panerai, 2003; Nakashima et al., 2015). Accordingly, the increase in the number of traffic accidents during Ramadan compared to other months of the year (Kalafat et al., 2015), and increased incidence near Iftar time (Mehmood et al., 2015; Tahir et al., 2013) may be attributed to factors other than spatial disorientation.

\section{Limitations and conclusions}


We did not use a within- subjects design where each participant could have been tested when not fasting and at the different points of Ramadan fasting. It may have been preferable to include serial Rod and Frame testing sessions in the same participants, however, this was not carried out due to the vulnerability of the RFT to learning and practice effects, as alignment errors can be significantly decreased by only one retest (Noriaki, 1965). Then again, the computerized RFT has been used in many studies and shown to be sensitive enough to detect differences between control groups and other groups with different conditions, such as chronic neck pain (Docherty et al, 2012), diabetes mellitus (Abdul Razzak et al, 2015), or even between genders (Abdul Razzak et al, 2014). So the failure to detect any fasting effects is most likely due to its nonexistence, rather than the test's failure to detect them.

The present study conducted on non-fasting and Ramadan fasting young adults showed robustness of verticality perception to fasting status and point of fasting during Ramadan. Verticality perception was also unaffected by time-of-day effects in non-fasting and fasting groups at two different points of Ramadan. This study adds proof to other studies reporting heterogeneous effects of Ramadan fasting on cognitive function.

The Authors declare that there is no conflict of interest. 


\section{References}

1. Abdul Razzak, R., Bagust, J., Docherty, S., Hasan, Z., Irshad, Y., and Rabiah, A. (2014), "Menstrual phase influences gender differences in visual dependence: A study with a computerized rod and frame test", Journal of Cognitive Psychology, DOI: 10.1080/20445911.2014.976227.

2. Abdul Razzak, R., Bagust, J., Docherty, S., Hussein, W. and Al-Otaibi, A. (2015), “Augmented asymmetrical visual field dependence in asymptomatic diabetics: Evidence of subclinical asymmetrical bilateral vestibular dysfunction", Journal of Diabetes and Its Complications, Vol. 29, pp: $68-72$.

3. Ali, M.R., and Amir, T. (1989), "Effects of fasting on visual flicker fusion", Perceptual \& Motor Skills, Vol. 69, pp. $627-631$.

4. Alsharidah, A.M., Murtaza, G., Alsharidah, M.M., and Bashir, S. (2016), "Fasting in Ramadan affects cognitive and physiological function in normal subjects (Pilot Study)", Neuroscience \& Medicine, Vol. 7, pp. $60-69$.

5. Azizi, F. (2010), "Islamic fasting and health", Annals of Nutrition and Metabolism, Vol. 56 No. 4, pp. 273 - 282. doi: 10.1159/000295848 
6. Bagust, J. (2005), "A computer based version of the rod and frame test - preliminary observations on the use of a VDU screen and video eye glasses", Archives of Physical Medicine \& Rehabilitation, Vol. 86, pp. 1062 - 1064.

7. Bagust, J., Docherty, S., and Abdul Razzak, R. (2013), "Rod and frame alignment times increase when the frame is tilted", Psychology and Behavioral Sciences, 2, 66 - 72.

8. BaHammam, A.S., Alaseem, A.M., Alzakri, A.A., and Sharif, M.M. (2013a), "The effects of Ramadan fasting on sleep patterns and daytime sleepiness: An objective assessment", Journal of Research in Medical Sciences, Vol.18 No. 2, pp. 127 - 131.

9. BaHammam, A.S., Nashwan, S., Hammad, O., Sharif, M. M. and Pandi - Perumal, S. R. (2013b), "Objective assessment of drowsiness and reaction time during intermittent Ramadan fasting in young men: a case-crossover study", Behavioral and Brain Functions, Vol. 9, pp. 32.

10. Bahammam, A.S., Almushailhi, K., Pandi - Perumal, S. R., and Sharif, M.M. (2014), "Intermittent fasting during Ramadan: does it affect sleep?", Journal of Sleep Research, Vol. 23 No. 1 , pp. $35-43$.

11.Bonakdaran, S. (2016), "Physiology of Ramadan Fasting”, Journal of Fasting Health, Vol. 4 No. 2, pp. $64-69$.

12. Chamari, K., Briki, W., Farooq, A., Patrick, T., and Herrera, C.P. (2016), "Impact of Ramadan intermittent fasting on cognitive function in trained cyclists: a pilot study", Biology of Sport, Vol. 33 No. 1, pp. $49-56$.

13. Chtourou, H., Hammouda, O., Chaouachi, A., Chamari, K., and Souissi, N. (2012), "The effect of time-of-day and Ramadan fasting on anaerobic performances", International Journal of Sports Medicine, Vol. 33, pp. 142-147. 
14. Docherty, S., and Bagust, J. (2010), "From Line to Dots: an improved computerized rod and frame system for testing visual vertical and horizontal", BMC Research Notes, Vol. 19, pp. 3:9.

15. Docherty, D., Scharer, R., Bagust, J., and Humphreys, B.K. (2012), "Perception of subjective visual vertical and horizontal in patients with chronic neck pain: A cross-sectional observational study", Manual Therapy, Vol. 17, pp 133 - 138.

16. Dolu, N., Yüksek, A., Sizer, A., and Alay, M. (2007), “Arousal and continuous attention during Ramadan intermittent fasting", Journal of Basic Clinical Physiology and Pharmacology, Vol. 18 , pp. $315-322$.

17. Doniger, G.M., Simon, E.S., and Ziovotovsky, A.Z. (2006), “Comprehensive computerized assessment of cognitive sequelae of a complete 12-16 hour fast", Behavioural Neuroscience, Vol. 120 No.4, pp. $804-816$.

18. Durmer, J.S., \& Dinges, D.F. (2005), "Neurocognitive consequences of sleep deprivation", Seminars in Neurology, Vol. 25, pp. $117-129$.

19. Farooq, A., Herrera, C.P., Almudahka, F., and Mansour, R. (2015), “A prospective study of the physiological and neurobehavioral effects of Ramadan fasting in preteen and teenage boys", Journal of the Academy of Nutrition and Dietetics, Vol. 115 No. 6, pp. 889 - 897.

20. Hakkou, F., Wast, D. and Jaouen, C. (1988), “Does Ramadan impair vigilance and memory?”, Psychopharmacology, Vol. 96, pp. 213.

21. Hijazi, M.M.K. (2013), "Attention, visual perception and their relationship to sport performance in fencing”, Journal of Human Kinetics, Vol. 39, pp. 195 - 201. 
22. Kalafat, U.M., Topacoglu, H., Dikme, O., Dikme, O., Sadillioglu, S.,and Erdede, M.O. (2016), "Evaluation of the impact of the month of Ramadan on traffic accidents", International Journal of Medical Science and Public Health, Vol. 5 No. 3, pp. 543 - 546.

23. Kemeny, A., and Panerai, F. (2003), "Evaluating perception in driving simulation experiments", Trends in Cognitive Sciences, Vol. 7 No. 1, pp. 31 - 37.

24. Kermani, S. K., Khatony, A., Jalali, R., Rezaei, M., and Abdi, A. (2017), “Accuracy and Precision of Measured Blood Sugar Values by Three Glucometers Compared to the Standard Technique", Journal of Clinical and Diagnostic Research, Vol. 11(4), OC05-OC08. http://doi.org/10.7860/JCDR/2017/23926.9613

25. Lopez, C., Lacour, M., Ballester, M., Dumitrescu, M., Anton, J., Nazarian, B. et al. (2005), "Brain activation during subjective visual vertical judgement: a functional magnetic resonance imaging study", Gait and Posture, Vol. 21 No.1, pp. S49-50.

26. Margolis, S.A., and Reed, R.L. (2004), "Effect of religious practices of Ramadan on sleep and perceived sleepiness of medical students", Teaching and Learning in Medicine, Vol. 16(2), pp. $145-149$.

27. Mazibrada, G., Tariq, S., Pe'rennou, D., Gresty, M., Greenwood, R., and Bronstein, A.M. (2008), "The peripheral nervous system and the perception of verticality", Gait and Posture, Vol. 27, pp. 202-20 8.

28. Mehmood, A., Moin, A., Khan, I. Q., Mir, M., and Jooma, R. (2015), "Vulnerable road users are at greater risk during Ramadan -- results from road traffic surveillance data", Journal of the Pakistan Medical Association, Vol. 65 No.3, pp. 287-291. 
29. Monk, T. H., Buysee, D. J., Reynolds, C. F., Berga, S. L., Jarrett, D. B., Begley, A. E. and Kupfer D. J. (1997), “Circadian rhythms in human performance and mood under constant conditions", Journal of Sleep Research, Vol. 6, pp. 9 - 18.

30. Monk, T. H. (2005), “The post-lunch dip in performance”, Clinics in Sports Medicine, Vol. 24, e15-e23.

31. Najafabadi, M.G., Nikoukar, L.R., Memari, A., Ekhtiari, H., and Beygi, S. (2015), "Does Ramadan fasting adversely affect cognitive function in young females?", Scientifica, Article ID 432428, http://dx.doi.org/10.1155/2015/432428.

Nakashima, R., Iwai, R., Ueda, S., and Kumada, T. (2015), "Egocentric direction and position perceptions are dissociable based on only static lane edge information", Frontiers in Psychology, Vol. 6, No. 1837. doi: 10.3389/fpsyg.2015.01837.

32. Nooripoor, S., Ghorbani. R., Azizzadeh. F., Danai, N., and Yazdiha, M. S. (2012), "Evaluating the blood glucose measured via glucometry in diagnosis of hypoglycemia in neonates", Koomesh, Vol. 13(4), pp. $440-44$.

33. Noriaki, K. (1965), "A fundamental study of rod frame test". Japanese Psychological Research, Vol. 7 No. 2, pp. $61-68$.

34. Pollak, C. P., Wagner, D. R., Moline, M. L. and Monk, T. H. (1992), “Cognitive and motor performance in narcoleptic and normal subjects living in temporal isolation”, Sleep, Vol. 15, pp. $202-21$.

35. Pavlou, M., Bronstein, A.M., and Davies, R.A, (2013), "Randomized trial of supervised versus unsupervised optokinetic exercise in persons with peripheral vestibular disorders", Neurorehabilitation and Neural Repair, Vol. 27(3), pp. 208 - 218.

36. Pavlou, M., Davies, R.A., and Bronstein, A.M. (2006), "The assessment of increased sensitivity to visual stimuli in patients with chronic dizziness", Journal of Vestibular Research, Vol. 16(4-5), pp. $223-231$. 
37. Pavlou, M., Quinn, C., Murray, K., Spyridakou, C., Faldon, M., and Bronstein, A.M. (2011), "The effect of repeated visual motion stimuli on visual dependence and postural control in normal subjects", Gait \& Posture, Vol. 33(1), pp. 113 - 118.

38. Reilly, T., and Edwards, B. (2007), "Altered sleep-wake cycles and physical performance in athletes", Physiology and Behavior, Vol. 90, pp. 274-284.

39. Roky, R., Chapotot, F., Benchekroun, M., Benaji, B., Hakkou, F., Elkhalifi, H., and Buguet, A. (2003), "Daytime sleepiness during Ramadan intermittent fasting: polysomnographic and quantitative waking EEG study", Journal of Sleep Research, Vol. 122, pp. 95 - 101.

40. Roky, R., Herrera, C.P., and Ahmed, Q. (2012), "Sleep in athletes and the effects of Ramadan", Journal of Sports Science, Vol. 30, pp. $75-84$.

41. Roky, R., Iraki, L., HajKhlifa, R., Ghazal, N. L., and Hakkou, F. (2000), "Daytime alertness, mood, psychomotor performances, and oral temperature during Ramadan intermittent fasting", Annals of Nutrition and Metabolism, Vol. 44, pp. 101-107.

42. Romeas, T., and Faubert, J. (2015), "Assessment of sport specific and non-specific biological motion perception in soccer athletes shows a fundamental perceptual ability advantage over non-athletes for reorganizing body kinematics", Journal of Vision Vol. 5, No.15 (12), pp. 504.

43. Simmons, A. (2003), "Spatial perception from a Cartesian point of view", Philosophical Topics, Vol. 31, pp. $395-423$.

44. Souissi, N., Chtourou, H., Zouita, A., Dziri, C., and Souissi, N. (2012), "Effects of Ramadan intermittent fasting on postural control in judo athletes", Biological Rhythm Research. Vol. 44, pp. $237-244$. 
45. Souissi, N., Zouita, A., Chtourou, H., Ferchichi, H., Dziri, C., Abedelmalek, S., and Souissi, N. (2014), "The effect of Ramadan intermittent fasting on dynamic postural control in judo athletes", Biological Rhythm Research, Vol. 45 No.1, pp. 27 - 36.

46. Sprague, J.E. and Arbelaez, A.M. (2011), "Glucose counter-regulatory responses to hypoglycemia", Pediatric Endocrinology Review, Vol. 9 No.1, pp. 463 - 475.

47. Tahir, M.N., Macassa, G., Akbar, A.H., Naseer, R., Zia1, A., and Khan, S. (2013), "Road traffic crashes in Ramadan: an observational study", Eastern Mediterranean Health Journal, Vol. 19, Supplement 3.

48. Tian, H.H., Aziz, A.R., Png, W., Wahid, M.F., Yeo, D., and Png, A.L.C. (2011), "Effects of fasting during Ramadan month on cognitive function in Muslim athletes", Asian Journal of Sports Medicine, Vol. 2 No.3, pp. 145 - 153.

49. Vingerhoets, R. A. A., De Vrijer, M., Van Gisbergen, J. A. M., and Medendorp, W. P. (2009), "Fusion of visual and vestibular tilt cues in the perception of visual vertical", Journal of Neurophysiology, Vol. 101, pp. 1321 - 1333.

50. Waterhouse, J. (2010), "Effects of Ramadan on physical performance: chronobiological considerations", British Journal of Sports Medicine, Vol. 44, pp. 509 - 515.

51. William, P. N., and Thomas, M. H. (2011), "Neurologic Manifestations of Hypoglycemia, Diabetes -Damages and Treatments”, Prof. Everlon Rigobelo (Ed.), ISBN: 978-953-307-652-2.

52. Witkin, H., Lewis, H., Hertzman, M., Machover, K., Meissner, P., and Wapner, S. (1954), "Personality through perception”. New York: Harper. 
53. Zouabi, A., Quarck, G., Martin, T., Grespinet, M., and Gauthier, A. (2016), "Is there a circadian rhythm of postural control and perception of the vertical?", Chronobiology International, Vol. 33 No. 10, pp. $1320-1330$. 


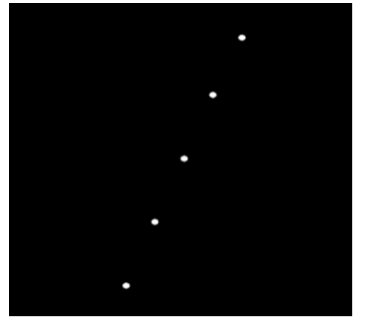

b) No Frame

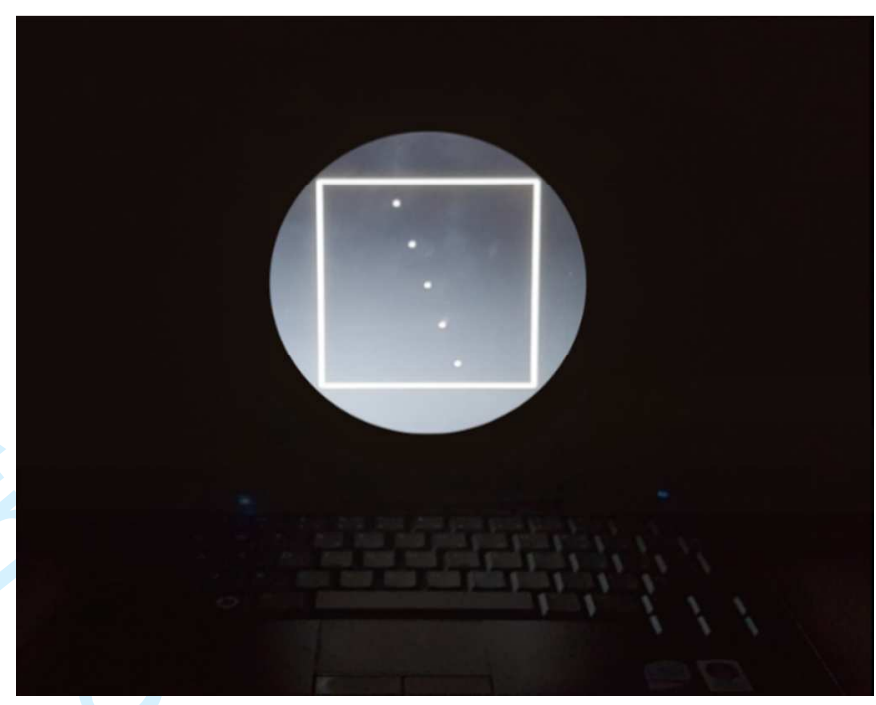

a)

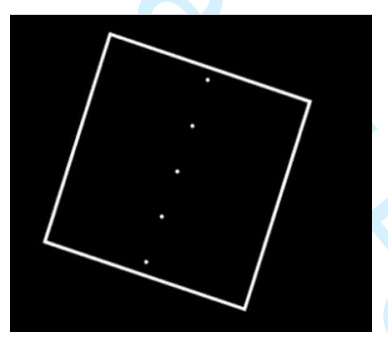

c) Frame $^{+18^{\circ}}$

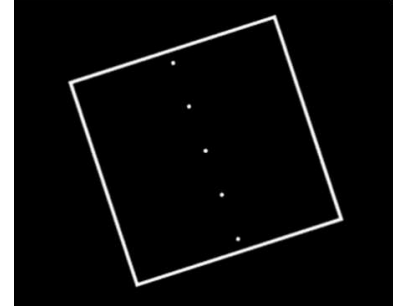

d) Frame -18 $^{\circ}$

Figure1. a) Set up of the Computerized Rod and Frame Test (CRFT) showing the concealment of the vertical edges of the laptop to obscure any cues of verticality from the subject. Presentations of rod and frame during testing: there were 4 trials for each presentation. SVV was assessed in: b) the absence of any frame surrounding the rod-as-points, and when there is a distracting frame tilted by 18 degrees in the clockwise and counter-clockwise direction respectively c) $\mathrm{Frame}^{+18^{\circ}}$ and d) Frame ${ }^{-18^{\circ}}$. The order of presentation was randomly assigned by the computer. 
Table1.

Descriptive statistics of blood glucose levels, sleep duration, SVV and Mean ${ }^{18^{\circ}}$ alignment errors

\begin{tabular}{|c|c|c|c|c|c|c|}
\hline Fasting Status & $\begin{array}{c}\text { Time of } \\
\text { Day }\end{array}$ & $\begin{array}{c}\text { Glucose Level } \\
\text { (mg/dl) }\end{array}$ & SVV $\left({ }^{\circ}\right)$ & $\operatorname{Mean}^{18^{\circ}}$ & $\begin{array}{c}\text { Sleep } \\
\text { Duration } \\
\text { (Hours) }\end{array}$ & $\mathbf{N}$ \\
\hline Non-fasting & & $87.6 \pm 13.4$ & $0.86 \pm 0.44$ & $1.34 \pm 0.64$ & $6.16 \pm 2.41$ & 19 \\
\hline Week1 Fasting & Morning & $88.8 \pm 10.1$ & $0.64 \pm 0.29$ & $1.26 \pm 0.53$ & $4.32 \pm 2.37$ & 11 \\
\hline Week3 Fasting & & $84.9 \pm 12.2$ & $0.84 \pm 0.52$ & $1.41 \pm 0.55$ & $4.25 \pm 2.31$ & 8 \\
\hline$P$ & & 0.88 & 0.35 & 0.86 & 0.07 & \\
\hline Non-fasting & & $86.1 \pm 15.4$ & $0.78 \pm 0.46$ & $1.28 \pm 0.53$ & $6.75 \pm 1.46$ & 20 \\
\hline Week1 Fasting & Afternoon & $76.3 \pm 7.8$ & $0.51 \pm 0.29$ & $0.97 \pm 0.37$ & $6.25 \pm 1.40$ & 10 \\
\hline Week3 Fasting & & $70.9 \pm 3.9$ & $0.50 \pm 0.28$ & $1.16 \pm 0.61$ & $6.50 \pm 1.65$ & 10 \\
\hline$P$ & & 0.005 & 0.99 & 0.30 & 0.68 & \\
\hline
\end{tabular}

The glucose level was measured in all participants just before the beginning of the verticality perception test. SVV refers to Subjective Visual Vertical which assesses the ability to perceive verticality and is an indicator of spatial orientation without any vertical reference.

Mean ${ }^{18^{\circ}}$ assesses verticality perception with distracting (tilted by $18^{\circ}$ ) visual cues and is a measure of visual dependence. It refers to the mean tilted frame score formed by calculating the mean of the absolute errors produced for the tilted frame ${ }^{+18^{\circ}}$ and tilted frame ${ }^{-18^{\circ}}$.

Sleep duration refers to hours of nocturnal sleep the participants had the night before the test.Week1 and Week 3 fasting status refer to testing carried out at the end of the first and third week of Ramadan fasting respectively.

Testing in the morning sessions was between 9:00 and 10:00 am, and that for afternoon sessions was between 4:00 and 5:00 pm. Values are Mean $\pm \mathrm{SD}$. $\mathrm{N}$ is the number of participants in each group. P-value is for comparison according to fasting status. 
a)

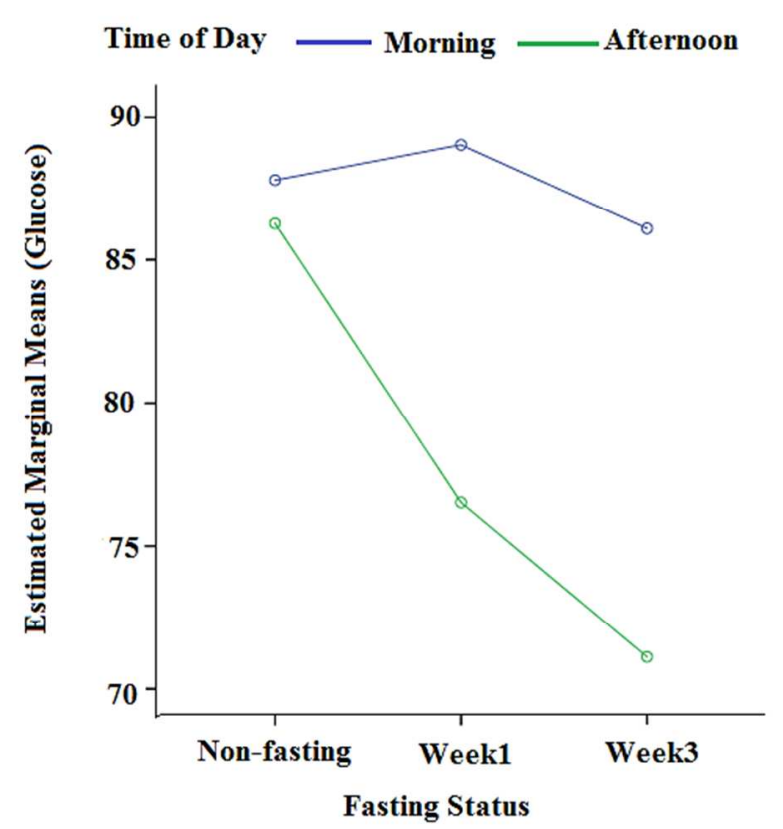

c)

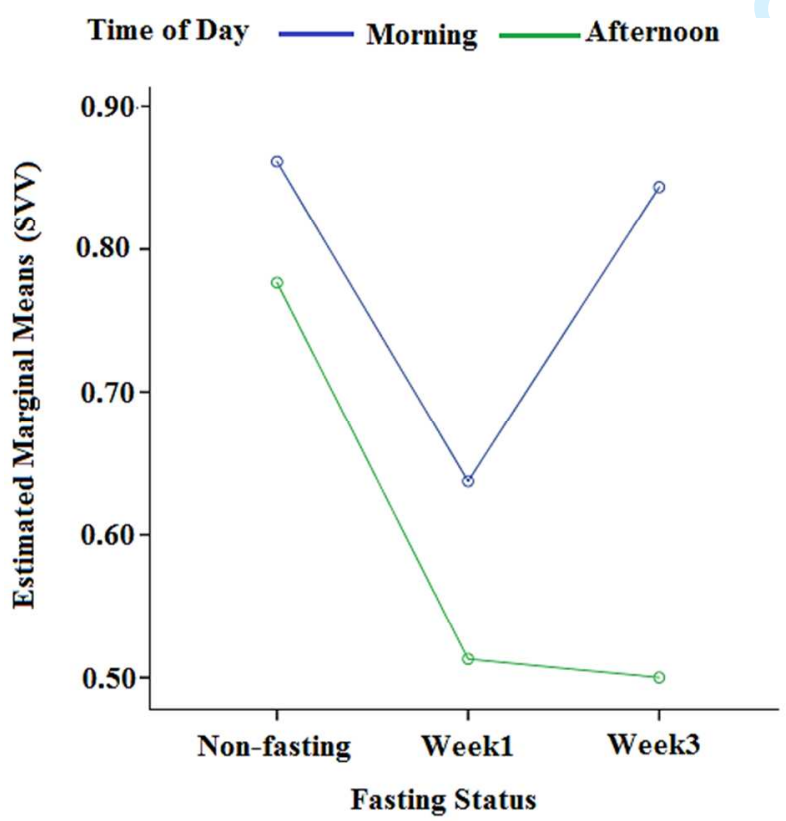

b)

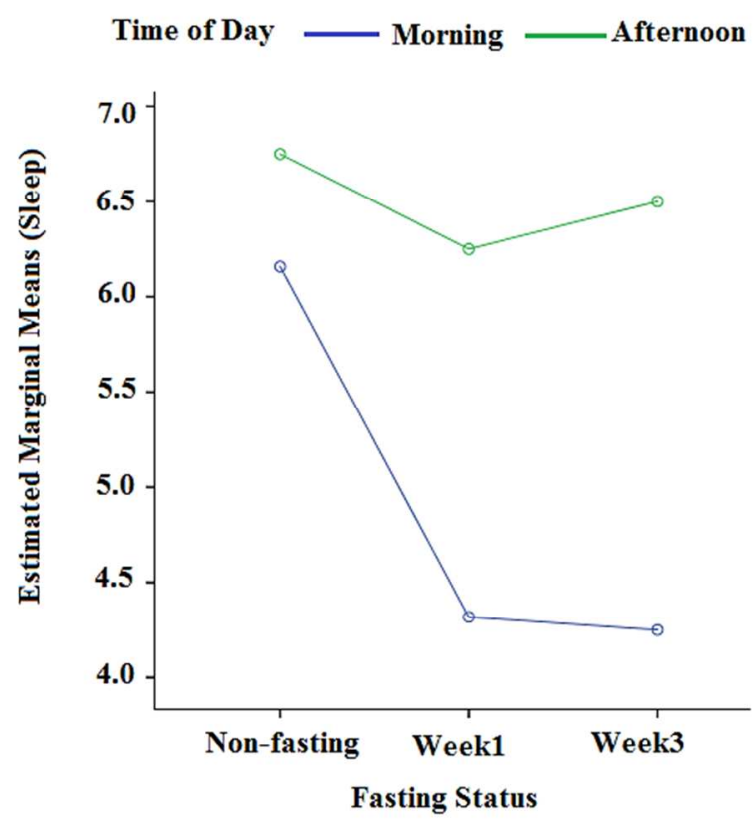

d)

Time of Day — Morning — Afternoon

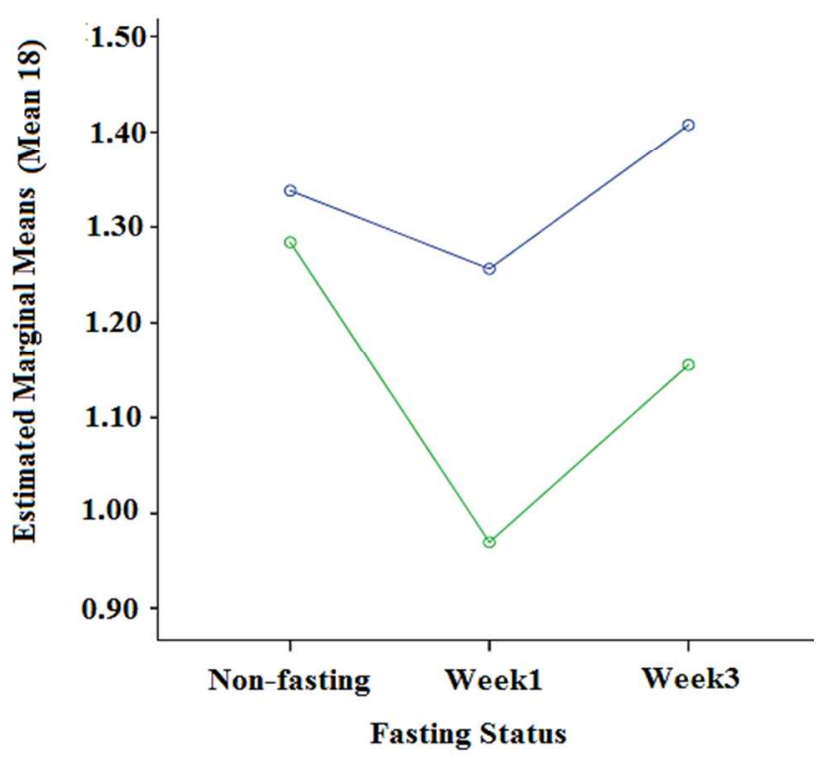

Figure 2. Interaction plot of estimated marginal means of: a) glucose concentration b) Sleep duration c) $\mathrm{SVV}\left({ }^{\circ}\right)$ and d) $\operatorname{Mean}^{18^{\circ}}$ alignment errors $\left({ }^{\circ}\right)$, calculated for time-of-day at each level of fasting status. Estimated marginal means is an indication of the mean response for each factor, adjusted for any other variables in the model.

The graphs show that there are no significant interactions between fasting status and time-of-day for any measured factor, since However, the main effect of fasting status was significant only for glucose level 
$(\mathrm{F}(2,72)=3.81, P=0.03)$, but the main effect of time-of-day was significant for both glucose level $(\mathrm{F}(1,72)$ $=7.60, P=0.007)$ and sleep duration $(\mathrm{F}(1,72)=8.85, P=0.004)$ only in the fasting participants. As for the vertical alignment errors, SVV and Mean ${ }^{18^{\circ}}$, the main effects of both fating status and time-of-day were not significant. 